\title{
IMPLEMENTATION OF SYSTEM DYNAMICS IN HOSPITAL SERVICES FOR IMPROVING THE INPATIENT ROOMS UTILIZATION
}

\author{
${ }^{\text {a}}$ Heri Supriyanto, ${ }^{\text {b Erma Suryani }}$ \\ ${ }^{\mathrm{a}, \mathrm{b}}$ Institut Teknologi Sepuluh Nopember \\ Jl. Raya ITS, Keputih, Kec. Sukolilo, Surabaya, 60111 \\ E-mail: aherisupriyanto3@gmail.com
}

\begin{abstract}
Hospitals are an important part of the health system. This agency consists of several main services, namely Outpatient, Emergency, and Inpatient services. One type of main service that is quite complex and needs to be considered is service at inpatient installations. Regarding this inpatient service, hospitals must make a structural and functional utilization effort to be further improved by increasing the utilization of service space regarding the number of available beds. To measure the level of utilization of hospital facilities at inpatient services, hospital service indicators are needed to measure it. These indicators include BOR (Bed Occupancy Rate), which is the percentage of beds filled, LOS (Length of Stay), namely the average length of stay, TOI (Turn Over Interval), which is the average free time of bed, BTO (Bed Turn Over), namely the productivity of the bed. The purpose of this study is to make modeling with a system dynamics so that the value of the indicator can have ideal parameter values. One reason for using this method is because it can help in system modeling that is complex, dynamic (changing over time), and non-linear. This method is unlike other methods that examine problems by sorting them into smaller and mutually limiting parts. This method has often been chosen also because of its dynamic complexity, and delayed feedback loops are embedded in it, so it proves to be very suitable for studying the reality being considered. The result of this study is that a scenario is needed to increase the number of patient visits, because patient visits are too low. This is evidenced by the value of the BOR which is less than the ideal value. In addition, the duration of patient care, day of care was influenced by the variable number of patient visits. The results of the scenario show that in 2019 to 2030 the values of BOR, LOS, TOI, and BTO were produced according to the ideal indicator value.
\end{abstract}

Key words: Inpatients, Room Utilization, Service Indicators, System Dynamics 


\section{INTRODUCTION}

Hospitals are an important part of the health system that plays an important role as a health service institution that provides health services in all fields and types of diseases. Hospitals also need to manage their services effectively and efficiently through services that satisfy patients by providing healing and care according to patient diagnoses, and satisfying staff by providing health and financial guarantees, hospital facilities, and a friendly work environment [1].

The quality of health services has been the subject of research in recent years as an important element of health care evaluations [2]. Service quality is a function of technical or clinical quality (quality of results) and functional or non-clinical quality (process quality), examples of technical quality such as skills, practice and procedure accuracy, and medical diagnosis, while functional or process quality refers to the method used on services provided to patients [3].

One type of service that is quite complex and needs to be considered is service at the inpatient installation. This installation is a combination of several service functions. The category of patients admitted to hospitalization are patients who need intensive care or close observation because of their illness and the need for adequate patient and nursing staff interaction in the ward or room environment and the disease itself requires more attention from nurses and doctors [4]. One of the performance improvements that must be considered by hospitals is inpatient services, especially hospital facilities, namely the use of beds [5]. That is because the number of patients served is hospitalized, depending on the number of beds provided.

To determine the level of utilization or utilization of space in inpatient services, indicators are needed. These indicators include BOR (Bed Ocupanccy Rate), which is the percentage of beds filled, LOS (Length of Stay), namely the average length of stay, TOI (Turn Over Interval), which is the average free time of bed, BTO (Bed Turn Over), namely bed productivity [6].

To judge, can use Barber Johnson charts. Barber Johnson's graph also serves to present data on the use of beds both in terms of medical and economic quality, by displaying the four indicators, namely BOR, LOS, TOI, and BTO. The indicator value of hospital services in this study in the past 3 years is as follows:

Table 1. Hospital Indicator Values.

\begin{tabular}{ccccc}
\hline Years & $\begin{array}{c}\text { BOR } \\
(\boldsymbol{\%})\end{array}$ & $\begin{array}{c}\text { LOS } \\
\text { (Days) }\end{array}$ & $\begin{array}{c}\text { TOI } \\
\text { (Days) }\end{array}$ & $\begin{array}{c}\text { BTO } \\
\text { (Times) }\end{array}$ \\
\hline 2016 & $58 \%$ & 2 & 2 & 53 \\
2017 & $53 \%$ & 2 & 2 & 53 \\
2018 & $49 \%$ & 2 & 3 & 49 \\
\hline
\end{tabular}

Based on these data, it can be seen in the 2016-2018 BOR value that the value decreases, while the ideal BOR parameter value is between $60-85 \%$ [6]. This shows that the use of beds used is still small by patients, compared to available beds. In other words, this small number of patients can cause economic income difficulties for the hospital. In addition, if viewed from the BTO value from 2016-2018 has an average value of 53, this BTO indicator is useful to see the number of times a hospital bed is used. While the recommended BTO ideal is a minimum of 4050 patients within a period of 1 year [6]. That is, 1 bed is expected to be used by an average of 40-50 patients in 1 year. This means that 1 patient is treated for an average of 9 days. This is in line with the recommended ideal LOS value, which is 3-12 days [7].

This inpatient service is very influential on the optimization of services in health facilities especially for hospitals. To assess the level of success about the state of services in hospitals is usually seen from various aspects such as the level of utilization of service facilities and infrastructure, service quality, and the level of service efficiency. To find out the level of utilization and optimization of hospital services, service indicators are needed.

This study, made a modeling with a system dynamics to analyze the utilization of space in inpatient services. This study takes the case of a private hospital, based on data visit (visit rate) inpatients in the last three years experienced a decrease in visits, namely in 2016 by 2,646 , in 2017 decreased by 2,487 , while in 2018 decreased, which is by 2,397 . The number of inpatient unit beds provided is in accordance with the type of hospital classification but has not been balanced with the number of patients who come, as many as 44 beds. While in this JKN era, there will be 
more hospital patients, if the patient is full in one of the wards / room then it will be moved to the ward that is still empty or to borrow another bed space that is still empty in a short period of time.

This research, will make a modeling with a system dynamics to improve the use of space in inpatient services. One reason for using this method is because it can help in system modeling that is complex, dynamic (changing over time), and non-linear. This method is unlike other methods that examine problems by sorting them into smaller and mutually limiting parts. This method has often been chosen also because of its dynamic complexity, and delayed feedback loops are embedded in it, so it proves to be very suitable for studying the reality being considered [8].

From previous research, in the research of Geranmayeh S, et al (2015), that this study contained the use of beds in emergency services (ED) with consideration of the number of patients who had different observation or treatment times depending on the patient's diagnosis . Another study from Cassettari L., M, et al. (2013), the case of this study is bed management in the emergency department, this is about patient visits which interfere with other hospital installation schedules due to the patient's emergency level. It can be seen that from the two previous studies, dynamic systems have the capability to represent a complex phenomenon in the field of health services.

According to Sterman (2000), to make modeling using this dynamic system, there are rules in making it such as determining the activity of selecting themes to be studied, determining key variables, planning time to consider the future into consideration and how far past events are to consider the future into consideration and how far past events from the root of the problem. In this study, for the case that will be modeled is how to increase the use of space in inpatient services so that the value of the service indicator will have the ideal value parameters.

In this study, for the case being modeled is how to use the use of space in the scope of inpatient services so that it has an indicator value which later has an ideal value. This study also includes strategies to be able to provide a decision to be able to improve the utilization of these beds by looking at the patient visits and beds that should be provided in the coming period, this research can also have a role in optimizing the inpatient service business process so that the treatment period the patient becomes optimal.

The key variables in this study consisted of the number of inpatient visits, length and days of service, and availability of hospital beds. In addition, the indicator data that became a reference in making this model are the last 14 years, 2005-2018. The results of this simulation could later predict an increase in the use of beds for the next few years. Therefore, this dynamic system method is very suitable to be used to model hospital service systems that have many complex service paths [9].

\section{MATERIAL AND METHODS}

\section{System Dynamics}

System Dynamics are methods for improving learning in complex systems [11]. The stages in the use of dynamic systems in this study adopted according to the methodology of the modeling process as proposed by Sterman (2000). Following are the steps as illustrated in Fig. 1 below.

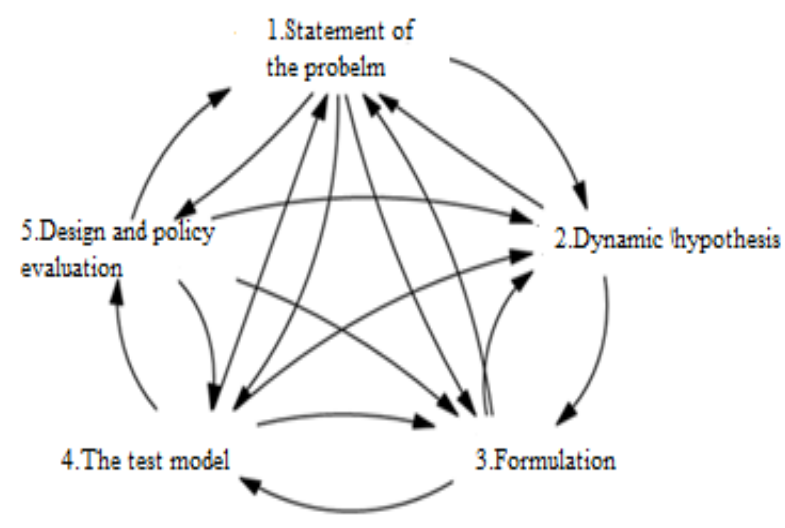

Fig. 1. Stages of System Dynamics

Then in Fig. 2 shows the stages that will be carried out in this study.

1. Defining Research Objects.

Defining the object of this study uses a case study approach, where this study aims to produce a model. 
2. Literature Study.

At this stage of the study an assessment of the related literature is carried out, such as those found in textbooks, experts, articles in relevant journals or previous research.

3. Data Collection.

At this stage the data collection is carried out as an important step, because it is an input for the model to be built.
4. System Modeling (Causal Loop Diagram). This stage is a system modeling (dynamic hypothesis), this stage is described in the form of a Kausatik Diagram (Causal Loop Diagram). This diagram is used to describe the system in general which will then be simulated with a system dynamics. approach such as Fig. 3 .

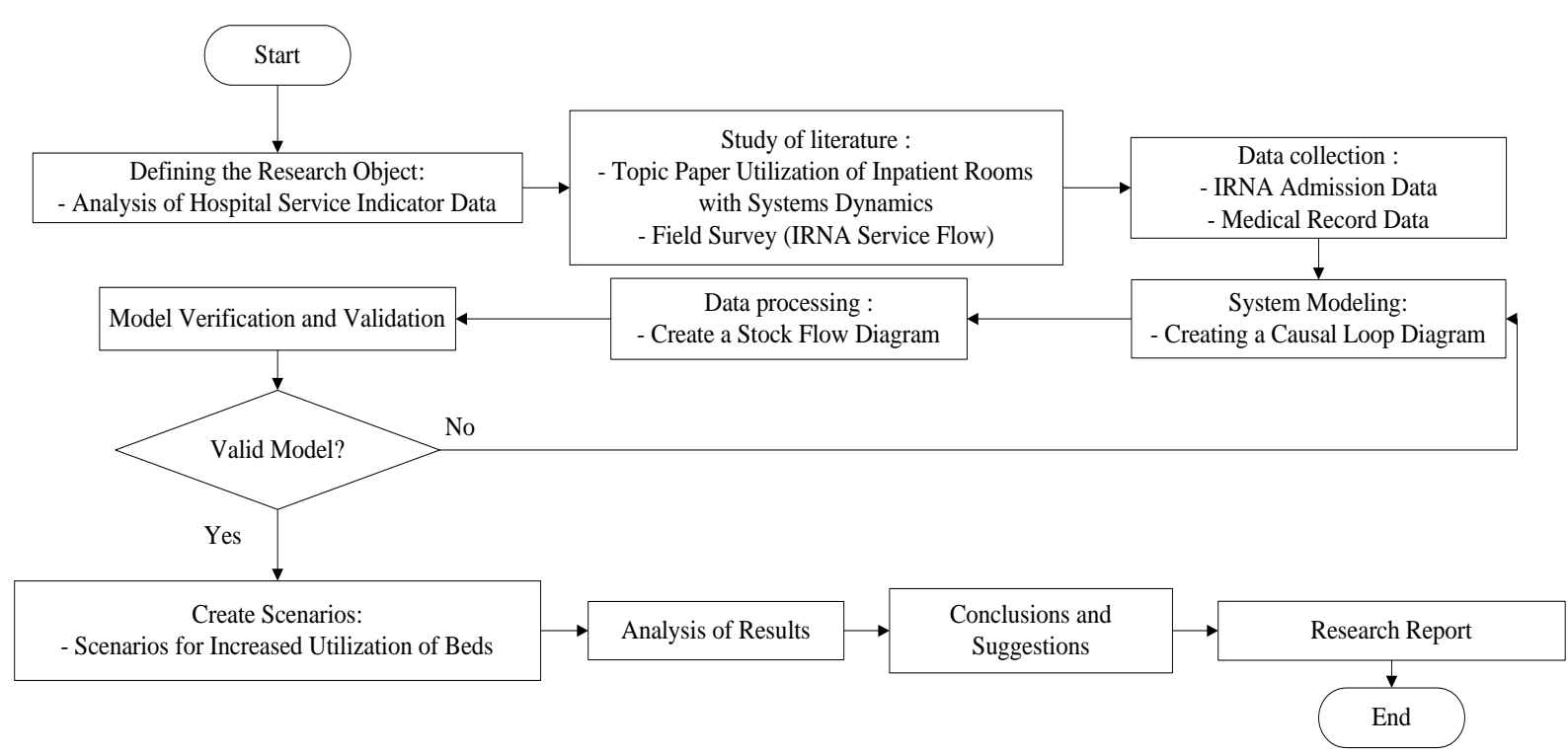

Fig. 2. Stages of Research

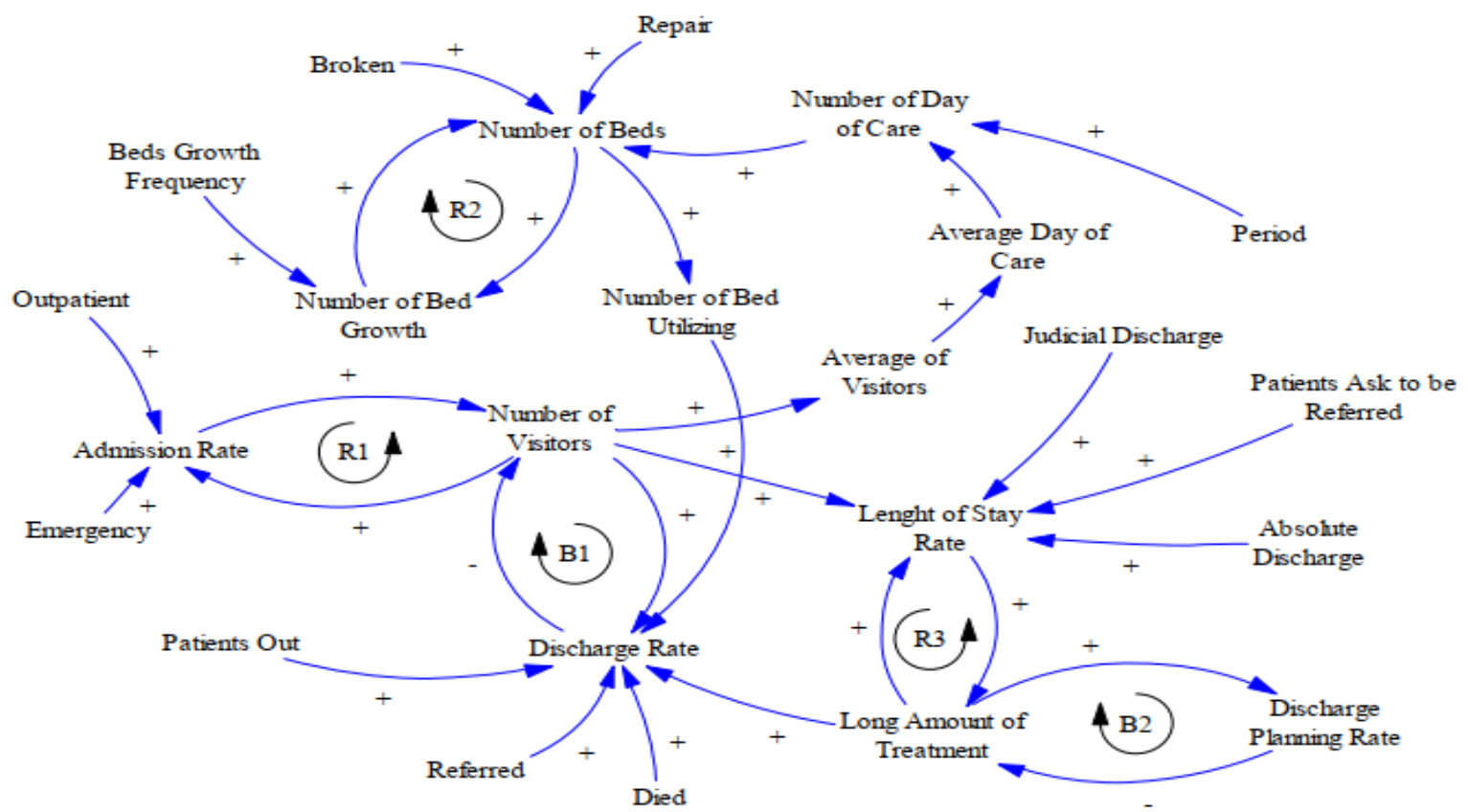

Fig. 3. Causal Loop Diagram Research 
5. Development of Stock and Flow Diagrams.

At this stage, from the central model that has been created, then the model will be translated into a dynamic system model that is described through stock and flow diagrams (flow diagram).

6. Verification and Validation.

The results of the flow diagram model that has been made will then be carried out by this process. Verification is the process of checking the model whether there has been no error while the Validation process for ascertain whether the model matches the actual system conditions.

This Validation process is carried out in two ways, namely model validation with tatistic Mean Comparison Test (mean comparison) or with model validation with a Comparison Test for Applied Variation (\% error variance) [12].

- Mean Comparison

$$
E 1=\left|\frac{\bar{S}-\bar{A}}{\bar{A}}\right|
$$

Note :

$\bar{S}=$ Average Value of Simulation Results

$\bar{A}=$ Data Average Value

The model is considered valid if $E 1 \leq 5 \%$.

- Amplitude Variation Comparison Test (\% Error Variance).

$$
\mathrm{E} 2=\left|\frac{\mathrm{S}_{\mathrm{s}}-\mathrm{S}_{\mathrm{a}}}{\mathrm{S}_{\mathrm{a}}}\right|
$$

Note:

$S \mathrm{~s}=$ Standard Deviation Model

$S \mathrm{a}=$ Standard Deviation

Model data is valid if $E 2 \leq 30 \%$.

1. Model Scenario.

At this stage, the model that has been made is given some treatment by creating scenarios (experiments) in the inpatient services business process to get more optimal services. Based on the Causal Loop Diagram produced from this study is to increase the use of inpatient service room facilities in the case of private hospitals. The scenario of research is increasing the use of hospital beds that aim to increase the use or use of available inpatient rooms so that the use of beds so they are not over loaded or never used.

2. Analysis and Discussion of Simulation Results.

Data from the model scenario simulation that has been made will then be analyzed to determine the factors that significantly influence the desired results, at this stage the best policies can be decided to improve the performance of inpatient services at the hospital.

3. Conclusions and Suggestions.

From the results of the analysis and discussion that has been carried out, the results of the conclusions will then be made and then provide suggestions relating to further research.

4. Compilation of Research Reports

This stage is the writing of the results of research and discussion of research results.

\section{RESULTS AND DISCUSSION}

1. Validation of Inpatient Patient Visits

Table 2. Validation of Patient Visits

\begin{tabular}{ccc}
\hline Years & Original Data & Simulation Data \\
\hline 2005 & 1602 & 1602 \\
2006 & 1542 & 1535 \\
2007 & 1482 & 1471 \\
2008 & 1417 & 1410 \\
2009 & 1352 & 1351 \\
2010 & 1287 & 1295 \\
2011 & 839 & 870 \\
2012 & 1081 & 1098 \\
2013 & 1131 & 1386 \\
2014 & 1815 & 1750 \\
2015 & 2499 & 2209 \\
2016 & 2646 & 2789 \\
2017 & 2487 & 2626 \\
2018 & 2397 & 2517 \\
Mean & 1684 & 1708 \\
STD & 591.625 & 593.673 \\
E1 & \multicolumn{3}{c}{$1.42 \%$} \\
E2 & \multicolumn{2}{c}{$0.35 \%$} \\
\hline
\end{tabular}


2. Validation Lenght and Day of Care

Table 3. Validation of length and Day of Care

\begin{tabular}{ccccc}
\hline Years & \multicolumn{2}{c}{ Length of Stay } & \multicolumn{2}{c}{ Days of Care } \\
\cline { 2 - 5 } & $\begin{array}{c}\text { Original } \\
\text { Data }\end{array}$ & $\begin{array}{c}\text { Simulation } \\
\text { Data }\end{array}$ & $\begin{array}{c}\text { Original } \\
\text { Data }\end{array}$ & Data \\
\hline 2005 & 3695 & 3695 & 5267 & 5268 \\
2006 & 3592 & 3583 & 5160 & 5049 \\
2007 & 3489 & 3476 & 4909 & 4839 \\
2008 & 3286 & 3377 & 4513 & 4637 \\
2009 & 3173 & 3283 & 4489 & 4444 \\
2010 & 2980 & 3195 & 4176 & 4259 \\
2011 & 1945 & 2075 & 2407 & 2860 \\
2012 & 2465 & 2447 & 3114 & 3611 \\
2013 & 2617 & 2971 & 4719 & 4559 \\
2014 & 4125 & 3715 & 5578 & 5755 \\
2015 & 5980 & 4831 & 7970 & 7266 \\
2016 & 6423 & 6590 & 8938 & 9174 \\
2017 & 5967 & 6471 & 7928 & 8637 \\
2018 & 5487 & 6173 & 7862 & 8277 \\
Mean & 3945 & 3992 & 5502 & 5617 \\
STD & 1443.5 & 1456.4 & 1952.1 & 1952.5 \\
E1 & \multicolumn{1}{c}{$1.19 \%$} & $2.08 \%$ \\
E2 & \multicolumn{2}{c}{$0.89 \%$} & $0.02 \%$ \\
\hline
\end{tabular}

3. Validation of Bed Use

Table 4. Validation of Use of Beds

\begin{tabular}{ccc}
\hline Years & $\begin{array}{c}\text { Original } \\
\text { Data }\end{array}$ & $\begin{array}{c}\text { Simulation } \\
\text { Data }\end{array}$ \\
\hline 2005 & 350 & 348 \\
2006 & 361 & 360 \\
2007 & 372 & 372 \\
2008 & 383 & 384 \\
2009 & 405 & 408 \\
2010 & 417 & 420 \\
2011 & 435 & 432 \\
2012 & 442 & 444 \\
2013 & 451 & 456 \\
2014 & 460 & 456 \\
2015 & 472 & 468 \\
2016 & 515 & 516 \\
2017 & 530 & 528 \\
2018 & 546 & 552 \\
Mean & 439 & 439 \\
STD & 62.309 & 62.922 \\
E1 & \multicolumn{2}{c}{$0.08 \%$} \\
E2 & \multicolumn{2}{c}{$0.98 \%$} \\
\hline
\end{tabular}

4. Scenario Development.

Scenario development is done to see the possibilities that occur in the future by simulating inpatient service data at hospitals, so that the data generated will be in accordance with the values of ideal inpatient service indicators. Scenarios are carried out from 2019 to 2030. The scenario in this study is to increase the utilization of hospital beds, this scenario aims to increase the level of use of one hospital facility, namely beds in inpatient services so that the use of beds is not used too often or many are not used. This scenario refers to the indicator value of hospital services so that it has the ideal parameter indicator value.

The first effort to increase the use of these beds is to increase the number of patient visits. Based on data obtained from the base model results, the average number of visits from 2005 to 2018 was 1708 patients with 46 beds available. The number of visits can be classified as small, because if there are an average of 142 patients per month, the average number of visits per day is 5 patients per day.

The level of patient visits is one of them affects the BOR value. Based on the identification of the model carried out previously, that the resulting BOR value is less than the ideal value, the ideal parameter on the BOR value indicator used at this xyz hospital is $75-85 \%$. This means that if the resulting BOR value $<75 \%$ and $>85 \%$ then the BOR is declared not ideal. According to Sudra (2010), a BOR value that is less than ideal indicates a lack of utilization of hospital care facilities, however if a high BOR number (more than $85 \%$ ) indicates a high utilization rate of beds, hospital development or additional beds are needed.

The first strategy is that the hospital marketing division must increase cooperation with insurance guarantees. The second strategy is marketing the facilities and products that are owned online or through the website. The third strategy is to create a patient member card program, this member card will later have benefits for patients to conduct care / examination. These benefits can be in the form of an inspection package or get a discount / cost discount at the time of inspection.

The second effort is to provide patient care as much as possible. Viewed based on the LOS indicator, from the medical aspect, that the longer the patient is treated, it shows poor medical quality performance because the patient must be treated longer (longer recovery). From the economic aspect, the longer the value of LOS means the higher the 
costs that will later have to be paid by patients to the hospital. Based on base model data from 2005-2018 produced, the value of this indicator shows the average length of patient care for 2 days. This is likely that the inpatient was discharged from the hospital prematurely, because the patient requested to be referred, or left at his own request. This reason was obtained based on the results of a survey of hospitals in this study. Things like this can have an impact on the use of beds that are not optimal so that the bed is not productive. Fig. 4 below is a scenario model to increase bed utilization

Based on the results of the model scenario produced, the following graph is a scenario of patient visit rates and utilization of bed. As shown in Fig. 5 and 6.

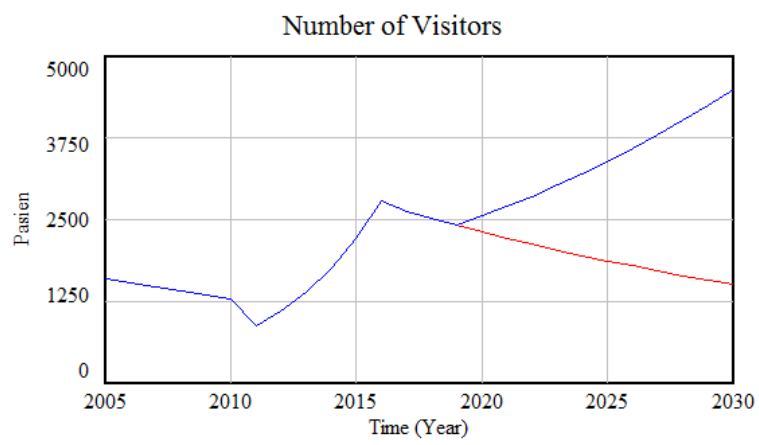

Number of Visitors : scenariomodel2030

Number of Visitors : basemodel2030

Fig. 5. Graph Number of Visitors

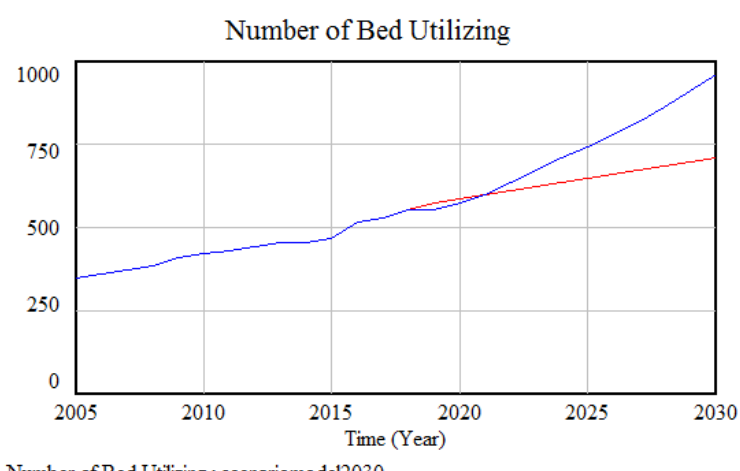

Number of Bed Utilizing : scenariomodel2030

Number of Bed Utilizing : basemodel2030

Fig. 6. Graph Number of Utilization of Beds.

\section{Analysis of Results}

From several scenarios that have been made, the author concludes some of these scenarios to give a clearer picture, which is shown in table 6 and table 7 .

The results of this scenario will be compared the results of the base model and the results of the scenarios to see service performance by looking at the value generated from hospital service indicators. The following are the ideal parameter values used by the hospital in this study.

Table 5. Ideal Parameter Value Indicator.

\begin{tabular}{cc}
\hline Ideal Parameters & Values \\
\hline BOR & $75-85 \%$ \\
TOI & $1-3$ days \\
BTO & $40-50$ times \\
LOS & $3-12$ days \\
\hline
\end{tabular}

Table 6. Data Analysis of Base Model Results

\begin{tabular}{cccccc}
\hline & \multicolumn{5}{c}{ Results of the Data Base Model } \\
\cline { 2 - 6 } Years & Visits & BOR & LO & TOI & BTO \\
& & & S & & \\
\hline 2019 & 2412 & $45 \%$ & 2 & 4 & 45 \\
2020 & 2312 & $42 \%$ & 2 & 4 & 42 \\
2021 & 2215 & $39 \%$ & 2 & 5 & 39 \\
2022 & 2123 & $37 \%$ & 2 & 6 & 37 \\
2023 & 2035 & $35 \%$ & 2 & 6 & 35 \\
2024 & 1950 & $33 \%$ & 2 & 7 & 33 \\
2025 & 1869 & $31 \%$ & 2 & 8 & 31 \\
2026 & 1791 & $29 \%$ & 2 & 8 & 29 \\
2027 & 1716 & $27 \%$ & 2 & 9 & 27 \\
2028 & 1645 & $25 \%$ & 2 & 10 & 26 \\
2029 & 1576 & $24 \%$ & 2 & 11 & 24 \\
2030 & 1511 & $23 \%$ & 2 & 12 & 23 \\
\hline
\end{tabular}




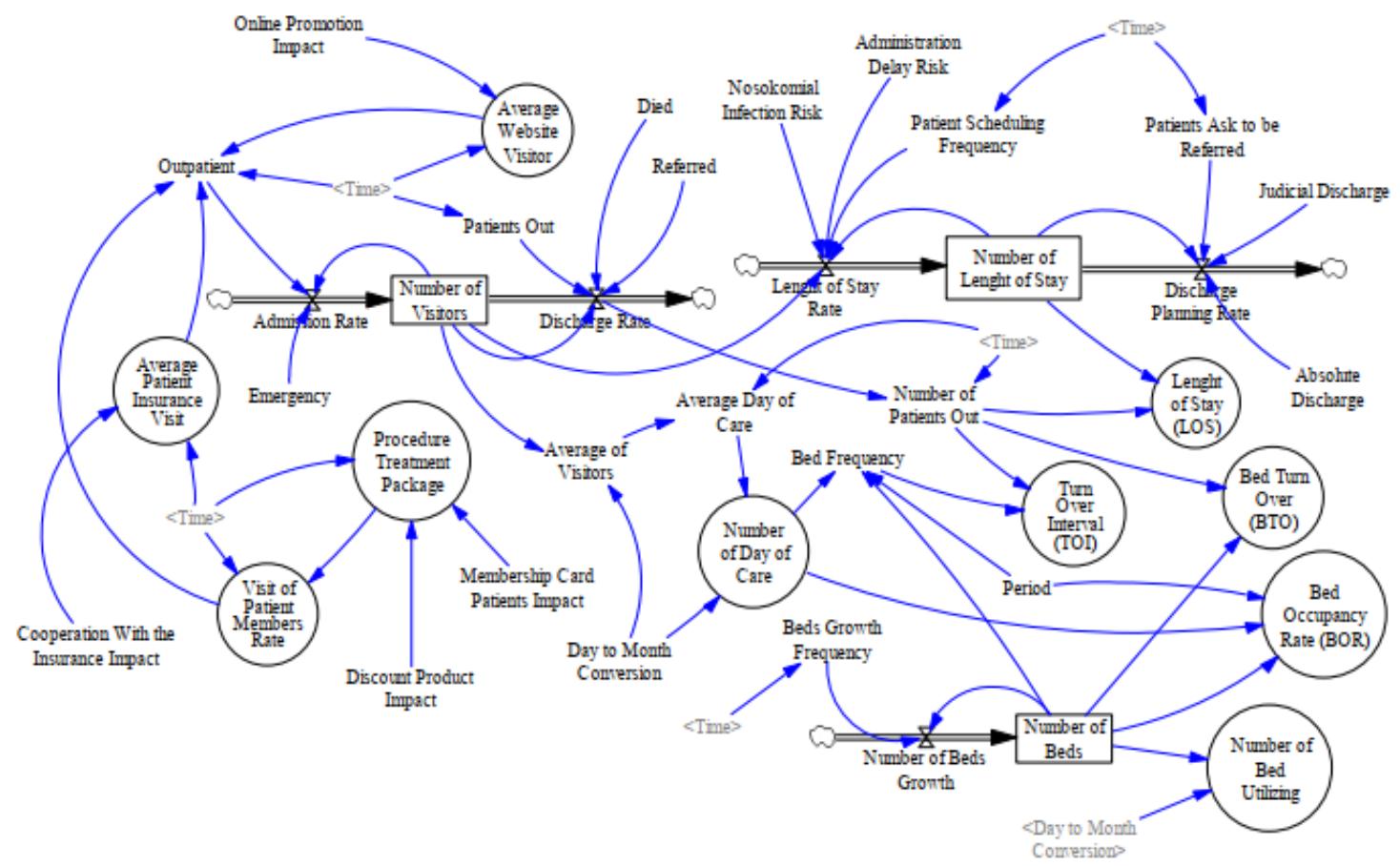

Fig. 4. Scenario model for Increasing the Utilization of Beds.

Table 6. Data Analysis of Base Model Results

\begin{tabular}{lccccc}
\hline & \multicolumn{5}{c}{ Results of the Data Base Model } \\
\cline { 2 - 6 } Years & Visits & BOR & LO & TOI & BTO \\
& & & S & & \\
\hline 2019 & 2412 & $45 \%$ & 2 & 4 & 45 \\
2020 & 2312 & $42 \%$ & 2 & 4 & 42 \\
2021 & 2215 & $39 \%$ & 2 & 5 & 39 \\
2022 & 2123 & $37 \%$ & 2 & 6 & 37 \\
2023 & 2035 & $35 \%$ & 2 & 6 & 35 \\
2024 & 1950 & $33 \%$ & 2 & 7 & 33 \\
2025 & 1869 & $31 \%$ & 2 & 8 & 31 \\
2026 & 1791 & $29 \%$ & 2 & 8 & 29 \\
2027 & 1716 & $27 \%$ & 2 & 9 & 27 \\
2028 & 1645 & $25 \%$ & 2 & 10 & 26 \\
2029 & 1576 & $24 \%$ & 2 & 11 & 24 \\
2030 & 1511 & $23 \%$ & 2 & 12 & 23 \\
\hline
\end{tabular}

Table 7. Data Analysis of Scenario Results.

\begin{tabular}{llllll}
\hline & \multicolumn{5}{c}{ Scenario Data Results } \\
\cline { 2 - 6 } Years & Visits & BOR & LOS & TOI & BTO \\
\hline 2019 & 2412 & $77 \%$ & 3 & 2 & 40 \\
2020 & 2553 & $79 \%$ & 3 & 1 & 40 \\
2021 & 2702 & $80 \%$ & 3 & 1 & 41 \\
2022 & 2859 & $80 \%$ & 3 & 1 & 41 \\
2023 & 3026 & $80 \%$ & 3 & 1 & 41 \\
2024 & 3203 & $80 \%$ & 3 & 1 & 41 \\
2025 & 3390 & $81 \%$ & 3 & 1 & 41 \\
2026 & 3587 & $77 \%$ & 3 & 1 & 42 \\
2027 & 3797 & $78 \%$ & 3 & 1 & 42 \\
2028 & 4018 & $78 \%$ & 3 & 1 & 42 \\
2029 & 4253 & $78 \%$ & 4 & 1 & 42 \\
2030 & 4501 & $79 \%$ & 4 & 1 & 42 \\
\hline
\end{tabular}

Based on the results of the service indicator values above, it shows that the overall results of the scenario data have obtained ideal hospital service indicator values. 


\section{CONCLUSION}

Data used in basemodel from 2005 to 2018. As for scenarios from 2019 to 2030. 2. The average length of care of patients is influenced by several factors such as determining the diagnosis that is not appropriate, giving inaccurate actions or procedures, infected with nosocomial diseases, administrative delay. 3. The ideal value of the BOR is $75-85 \%$. Judging from the results of the scenario shows that the BOR has a value with an ideal range of values each year. While the BOR value at the basemodel is still below average at $75 \%$.

For the ideal value of LOS is 3 - 12 days, the basemodel results show that the overall value of LOS is 2 days, this shows that the value of LOS is still not ideal, whereas in the results of the scenario, the average value of LOS is 3 days, but in 2029 and 2030 is 4 days. This shows that the LOS value produced is

\section{REFERENCES}

[1], O. O. A. Hospital Management in the (0s: Fundholding Consultants? Journal of nagement in Medicine, 8(1), 64-70. 10.1108/02689239410052586. 1994.

[2] Labarere, J., Francois, P., Auquier, P., Robert, C. and Fourny, M. "Development of a French inpatient satisfaction questionnaire", International Journal for Quality in Health Care, Vol. 13 No. 2, pp. 99-108. 2001

[3] Zarei, A., Arab, M., Rahimi, A., Rashidian, A. and Ghazi, M. "Service quality of private hospitals: the Iranian patients' perspective", BMC Health Services Research, Vol. 12 No. 1, Article No. 31. 2012.

[4] Senarath, U., Gunawardena, N. S., Sebastiampillai, B., Senanayake, A., Lekamge, S., Seneviratna, A., Wijeratne, D. Patient satisfaction with nursing care and related hospital services at the National Hospital of Sri Lanka. Leadership in Health Services, 26(1), 6377. 2013.

[5] Young-ho Oh., Optimal Supply and the ideal, which means that the patient's care is in accordance with the patient's diagnosis so that the utilization of available beds becomes productive. For the ideal value of TOI value is 1-3 days, the results from basemodel results show that the average value is more than 3 days while the results of the scenario are an average of 1 day, this shows that the results of the scenario value are ideal TOI indicator values that means that the utilization interval of the bed has been productive.

While the BTO ideal value is 40-50 times in 1 year. Basemodel value shows the average value produced is 33 days, this indicates that the frequency of use of beds is low, meaning that many beds are not used, while the results of the scenario averaged 41 days. This value shows the ideal BTO value which means that the use of the bed is optimal.

Efficient Use of Hospital Bed Resources in Korea. Korea Institute for Health and Social Affairs.ISBN: 978-89-6827-319-3 93510. 2015.

[6] Depkes RI, Profil Kesehatan Indonesia. Jakarta. 2005.

[7] Sudra, Rano Indradi. Statistik Rumah Sakit - Dari Sensus Pasien \& Grafik Barber Jhonson Hingga Statistik Kematian \& Otopsi. Graha Ilmu : Yogyakarta. 2010.

[8] Homer, J. B. and Hirsch G. B. System Dynamics Modelling for Public Health: Background and Opportunities. In Am J Public Health 96(3). 2006.

[9] Geranmayeh S, Appa I.S. Capacity analysis of critical hospital resources using system dynamic approach. 2015.

[10] Cassettari L., Mosca R., Orfeo A., Revetria R., Rolando F. and Morrison J. A. System Dynamics Study of an Emergency Department Impact on the Management of Hospital's Surgery Activities. DOI: 10.5220/0004617205970604. 2013. 
36 Jurnal Ilmiah KURSOR Vol. 10, No. 1, Juli 2019, hlm. 29-36

[11] Sterman, J. Business Dynamics: Systems thinking and modeling for a complex world, McGrawHill/Iriwin. 2000.
[12] Barlas Y. 1989. "Multiple Tests for Validation of System Dynamics Type of Simulation Models." European Journal of Operational Research 42 (1): 59-87. doi:10.1016/0377-2217(89)90059-3. 1989. 